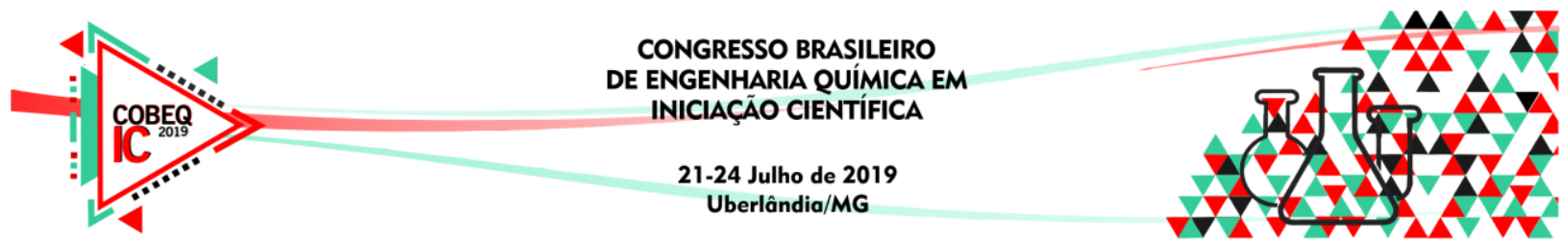

\title{
POTENCIAL ENERGÉTICO DE RESÍDUOS SÓLIDOS URBANOS POR DIFERENTES MODELOS TÉCNICOS DE PREVISÃO
}

\author{
T. F. SILVA ${ }^{1}$ e I. R. FREITAS ${ }^{1}$ \\ ${ }^{1}$ Centro Universitário do Norte Paulista, Curso de Engenharia Química \\ E-mail para contato: thaise.6_fernanda@hotmail.com; irfreitas@yahoo.com.br
}

\begin{abstract}
RESUMO - A decomposição da matéria orgânica em aterros sanitários produz o gás de metano. A emissão descontrolada desse gás pode ser uma ameaça ao meio ambiente. Nesse sentido, este trabalho apresenta uma estimativa da geração de biogás procedente da decomposição dos resíduos sólidos em aterros sanitários. Para realizar a estimativa dos parâmetros foram utilizados os modelos United States Environment al Protection Agency (USEPA) e Biogás (CETESB), que mostraram resultados diferentes quando feita a comparação. Para o USEPA, existe uma produção de biogás acumulada de $38.177,09 \mathrm{~m}^{3} / \mathrm{ano}$, com uma energia acumulada de $1.427,15 \mathrm{MWh} /$ dia e potência média de geração de 68,35 MW. Para o modelo Biogás, a produção acumulada é de 5.795,46 $\mathrm{m}^{3}$ /ano, com uma energia acumulada de $216,55 \mathrm{MWh} /$ dia, para uma potência média de geração de 10,37 MW. Portanto, o uso do gás de aterro pode promover vários benefícios, entre eles destacam-se a diminuição de emissão dos gases do Efeito Estufa, além de oportunidades de geração e recuperação de energia.
\end{abstract}

\section{INTRODUÇÃO}

O crescimento demográfico e o aumento do nível de renda em grande parte da população têm provocado um crescimento elevado da produção de resíduos e uma maior complexidade na composição dos mesmos. Dessa situação, surge a problemática da disposição final dos resíduos sólidos, cuja quantidade gerada torna-se cada vez maior. Estes resíduos possuem um potencial emissor de gases que contribuem com o efeito estufa (ALVES et al. 2015).

Os resíduos sólidos urbanos, quando em ambiente redutor sob condições anaeróbias, sofrem decomposição e, a partir de sua parcela de matéria orgânica, ocorre à liberação de biogás, o qual é uma mistura gasosa que contém, dentre outros gases, o metano $\left(\mathrm{CH}_{4}\right)$, com potencial de aproveitamento energético. Quanto maior a fração de metano, mais energia por unidade de massa o biogás contém (JACO, 2012).

A geração de energia em aterros sanitários torna-se um empreendimento atrativo, pois ao mesmo tempo em que se dá uma destinação adequada aos resíduos por não terem mais valor para a sociedade, utiliza o produto desta decomposição, o biogás, para geração de energia. Além do mais, a emissão descontrolada do biogás pode ser uma ameaça ao meio 


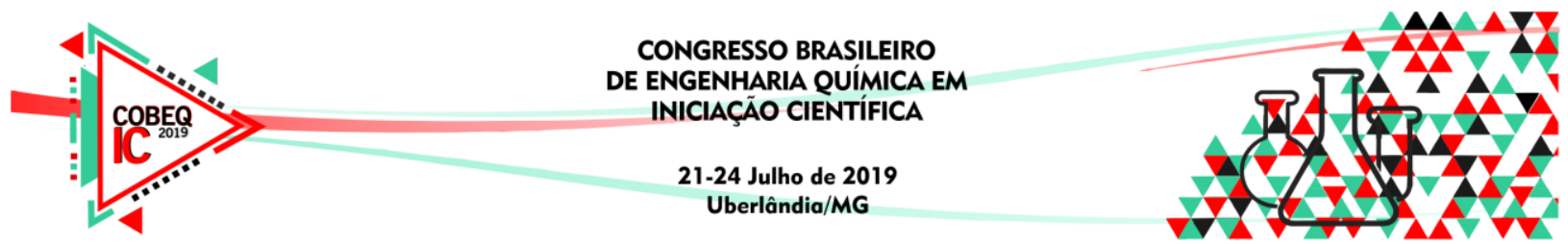

ambiente, causando danos à vegetação, gerando odores desagradáveis e oferecendo risco de explosão em concentrações elevadas (SANTOS et al. 2016).

Em função deste contexto, a captação do gás produzido em aterros é de grande importância, pois diferentes fontes de energia alternativa podem diversificar ou incrementar a geração do biogás em aterros sanitários. $\mathrm{O}$ aproveitamento energético do biogás gerado em aterro, constitue-se numa alternativa interessante, uma vez que o crescimento econômico do país demanda cada vez mais a disponibilização de energia (SILVA, 2012).

Diante das informações obtidas, o objetivo deste trabalho foi verificar o potencial energético de resíduos de sólidos urbanos de cidades da Região Noroeste Paulista por diferentes modelos técnicos de previsão.

\section{MATERIAL E MÉTODOS}

O presente trabalho foi conduzido, com base em dados referentes à quantidade de Resíduos Sólidos Urbanos depositados nos principais aterros sanitários da Região Noroeste Paulista referente ao ano de 2016. Os dados foram obtidos junto a Companhia Ambiental do Estado de São Paulo (CETESB), onde foi feito o levantamento das cidades que possuem aterros e maior quantidade de resíduos depositados.

Para estimativa preliminar da produção de gás metano, foi utilizado o método conhecido como Aproximação Simples da United States Environment al Protection Agency (USEPA), proposto por AUDIBERT (2011) conforme a equação 1.

$$
\mathrm{E}_{\mathrm{CH} 4}=\text { Gr.MSWd }
$$

Onde:

$\mathrm{E}_{\mathrm{CH} 4}=$ geração anual de gás metano $\left(\mathrm{m}^{3} / \mathrm{ano}\right)$;

$\mathrm{Gr}=$ geração de gás metano por quantidade de resíduos de $0,7805\left(\mathrm{~m}^{3} / \mathrm{kg}\right.$ ano $)$.

MSWd = quantidade de resíduo disposto $(\mathrm{kg})$.

O modelo de primeira ordem de Scholl Canyon que é o método recomendado pelo Banco Mundial para estimar a geração de metano no aterro, foi utilizado (equação 2).

$\mathrm{Q}_{(\mathrm{CH} 4) \mathrm{i}}=\mathrm{k} \mathrm{x} \mathrm{L}_{\mathrm{o}} \times \mathrm{m}_{\mathrm{i}} \times \mathrm{e}^{-\mathrm{k} . \mathrm{ti}}$

Onde:

$\mathrm{Q}_{(\mathrm{CH} 4) \mathrm{i}}=$ metano produzido do ano i a partir da seção i do resíduo, $\left(\mathrm{m}^{3} / \mathrm{ano}\right)$.

$\mathrm{k}=$ taxa de geração de metano (anos-1).

$\mathrm{L}_{\mathrm{o}}=$ potencial da geração de metano $\left(\mathrm{m}^{3} \mathrm{CH}_{4} / \mathrm{t}\right.$ resíduo $)$.

$\mathrm{mi}=$ massa de resíduo despejada no ano i (t/ano).

$\mathrm{ti}=$ anos após o fechamento. 


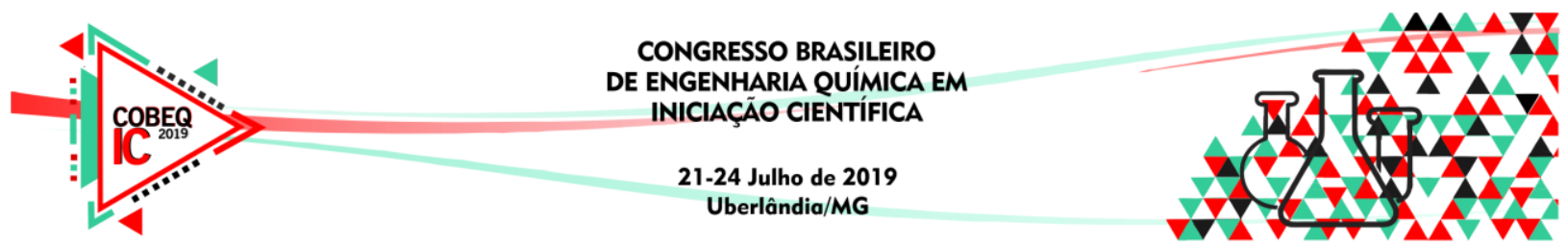

O potencial de geração de metano $\left(\mathrm{L}_{0}\right)$ que representa a produção total por tonelada de lixo foi utilizado o recomendado pelo Banco Mundial, cujo valor preestabelecido de $\mathrm{L}_{\mathrm{o}}$ é de $170 \mathrm{~m}^{3}$ de metano/tonelada de resíduos.

Foi utilizado o modelo Biogás (CETESB), conforme Pinãs et al. (2016), para estimativa da geração de metano de aterro sanitário e comparação com o modelo USEPA.

$\mathrm{Q}_{\mathrm{x}}=\mathrm{k} \mathrm{R}_{\mathrm{x}} \mathrm{L}_{0} \mathrm{e}^{\mathrm{k}(\mathrm{x}-\mathrm{T})}$

Onde:

$\mathrm{Q}_{\mathrm{x}}=$ vazão de metano $\left(\mathrm{m}^{3} \mathrm{CH}_{4} / \mathrm{ano}\right)$;

$\mathrm{k}=$ constante de decaimento (1/ano);

Lo = potencial de geração de biogás $\left(\mathrm{m}^{3} /\right.$ ton $)$;

$\mathrm{Rx}=$ fluxo de resíduos (t/ano);

$\mathrm{x}=$ ano atual;

$\mathrm{T}=$ ano de deposição do resíduo.

As equações utilizadas nesses modelos têm em comum o fato de serem equações cinéticas de primeira ordem. Para a determinação da estimativa da potência e energia disponível, foi utilizado o método proposto por Alves et al. (2015), conforme as equações 4 e 5 .

$$
\mathrm{P}=\frac{\mathrm{Q} \times \mathrm{PCI} \times \eta}{860.000}
$$

$$
\mathrm{E}=\mathrm{P} \times \text { Rend } \mathrm{x} \text { Tempo de Operação }
$$

Onde:

$\mathrm{P}=$ Potência disponível (MW);

$\mathrm{Q}=$ Geração anual de metano por ano calculado $\left(\mathrm{m}^{3} \mathrm{CH}_{4} / \mathrm{ano}\right)$;

$\mathrm{PCI}=$ Poder calorífico inferior do metano $\left(\mathrm{kcal} / \mathrm{m}^{3} \mathrm{CH}_{4}\right)$;

$\eta=$ Eficiência dos motores (em média, 0,28 );

860.000 = Conversão de kcal/h para MW;

$\mathrm{E}=$ Energia disponível (MWh/dia);

Rend $=$ Rendimento de motores operando a plena carga (estimado em 0,87);

Tempo de operação = Tempo de operação dos motores.

Portanto, em função da vazão de metano, é possível realizar os cálculos da potência (MW) e de energia (MWh/dia) disponíveis no aterro para isso, considerou-se: aterro;

$\mathrm{PCI}_{\mathrm{CH} 4}=5.500 \mathrm{kcal} / \mathrm{m}^{3}$, valor adotado supondo $50 \%$ de metano presente no biogás de

Tempo de operação dos motores $=24$ horas/dia. 


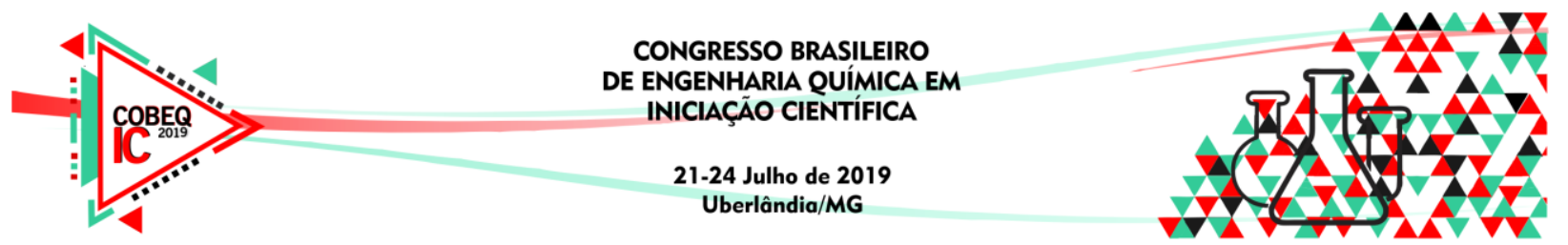

\section{RESULTADOS E DISCUSSÃO}

- Modelo técnico de previsão da United States Environment al Protection Agency

Estima a geração de metano e não as emissões, pois parte do metano em sua migração para a atmosfera é captado e degradado nas camadas mais superficiais do terreno, com isso considera-se que todo o metano gerado é emitido à atmosfera através de fissuras ou vias de evacuação existente no local (SOUZA et al. 2011). Os resultados do potencial de geração de biogás pelo modelo da United States Environment al Protection Agency (USEPA) para o cenário do ano de 2016, estão demonstrados na Tabela 1.

Tabela 1 - Potencial de geração de biogás pelo modelo USEPA.

\begin{tabular}{lccc}
\hline \multirow{3}{*}{ Municípios } & \multicolumn{3}{c}{ Ano de 2016 } \\
\cline { 2 - 4 } & ton/dia & ton/ano & $\begin{array}{c}\mathbf{E}_{\mathbf{C H 4}} \\
\left(\mathbf{m}^{\mathbf{3}} / \mathbf{a n o}\right)\end{array}$ \\
\hline Catanduva & 107,22 & $39.135,30$ & $30.545,10$ \\
Potirendaba & 10,60 & $3.869,00$ & $3.019,75$ \\
Tanabí & 16,19 & $5.909,35$ & $4.612,24$ \\
\hline Total & 134,01 & $48.913,65$ & $38.177,09$ \\
\hline \multicolumn{1}{c}{ Fonte: Elaborado pelos autores. }
\end{tabular}

- Modelo técnico de previsão Biogás (CETESB)

O modelo Biogás (CETESB) gera dados apenas de emissões de metano pela decomposição anaeróbia dos resíduos sólidos urbanos. A característica deste modelo é permitir a geração de potência a partir dos dados ingressados da população (ALVES et al. 2015). Os resultados do potencial de emissão de metano $\left(\mathrm{m}^{3} \mathrm{CH}_{4} /\right.$ ton) pelo modelo Biogás (CETESB) estão apresentados na Tabela 2.

Tabela 2. Potencial de geração de biogás pelo modelo Biogás (CETESB).

\begin{tabular}{lccc}
\hline \multirow{2}{*}{ Municípios } & \multicolumn{3}{c}{ Ano de 2016 } \\
\cline { 2 - 4 } & ton/dia & ton/ano & $\begin{array}{c}\mathbf{E}_{\mathbf{C H 4}} \\
\left(\mathbf{m}^{3} / \mathbf{a n o}\right)\end{array}$ \\
\hline Catanduva & 107,22 & $39.135,30$ & $4.643,38$ \\
Potirendaba & 10,60 & $3.869,00$ & 456,35 \\
Tanabí & 16,19 & $5.909,35$ & 695,72 \\
\hline Total & 134,01 & $48.913,65$ & $5.795,46$ \\
\hline \multicolumn{1}{c}{ Fonte: Elaborado plos autores } & & \\
\hline
\end{tabular}

Fonte: Elaborado pelos autores.

Após a avaliação das metodologias teóricas para estimativa de geração de gás metano, o modelo USEPA apresenta os resultados com maior potencial de geração, uma vez que o valor de " $\mathrm{k}$ " encontrado para este modelo é superior ao obtido em Biogás (CETESB). A diferença está entre os valores de "k", que de acordo com o que foi anteriormente citado, esta variável é apresentada na formulação do modelo USEPA como taxa de geração de metano 


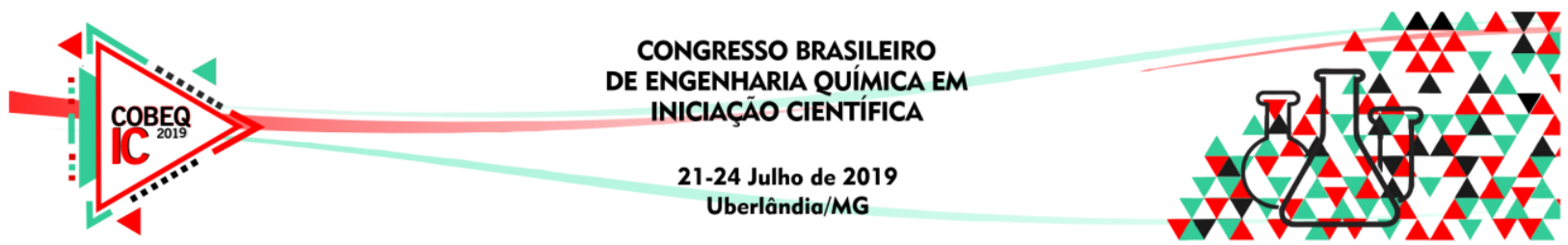

(anos-1) e por Biogás (CETESB) é definida como constante de decaimento (1/ano). Segundo Silva (2012) quanto maior a idade do resíduo aterrado $(\mathrm{x}-\mathrm{t})$, menor será o valor da vazão $\left(\mathrm{Q}_{\mathrm{x}}\right)$. Portanto, acarreta uma geração de biogás mais lenta no modelo Biogás (CETESB) em relação ao outro modelo.

- Estimativa da potência e energia disponíveis nos aterros.

A Tabela 3 apresenta os resultados do cálculo do potencial energético de gás metano para os aterros sanitários.

Tabela 3 - Potencial energético de biogás pelos modelos USEPA e Biogás (CETESB).

\begin{tabular}{lcccc}
\hline \multirow{2}{*}{ Municípios } & \multicolumn{2}{c}{ USEPA } & \multicolumn{2}{c}{ Biogás (CETESB) } \\
\cline { 2 - 5 } & $\begin{array}{c}\text { Potência } \\
(\mathbf{M W})\end{array}$ & $\begin{array}{c}\text { Energia } \\
(\mathbf{M W h} / \mathbf{d i a})\end{array}$ & $\begin{array}{c}\text { Potência } \\
(\mathbf{M W})\end{array}$ & $\begin{array}{c}\text { Energia } \\
(\mathbf{M W h} / \mathbf{d i a})\end{array}$ \\
\hline Catanduva & 54,7 & $1.142,14$ & 8,32 & 173,73 \\
Potirendaba & 5,40 & 112,75 & 0,81 & 16,92 \\
Tanabi & 8,25 & 172,26 & 1,24 & 25,90 \\
\hline Total & 68,35 & $1.427,15$ & 10,37 & 216,55 \\
\hline
\end{tabular}

Fonte: Elaborado pelos autores.

O levantamento do potencial energético dos aterros foi realizado com base no potencial de geração do gás metano, sendo $38.177,09 \mathrm{~m}^{3} /$ ano pelo modelo USEPA e 5.795,46 $\mathrm{m}^{3}$ /ano por Biogás (CETESB). Para a obtenção de uma estimativa do potencial energético, considerando que não houve acesso a dados específicos, como composições e características dos aterros citados. Tendo em vista que esse tipo de estimativa é um importante pressuposto para avaliação dos potenciais energéticos, faz-se necessário criar dois cenários. Um cenário otimista com potencial de 1.427,15 MWh/dia pelos dados referentes ao modelo USEPA, apresentando maior potencial e um cenário pessimista de $216,55 \mathrm{MWh} /$ dia por Biogás (CETESB).

\section{CONSIDERAÇÕES FINAIS}

A partir das informações expostas acima, o potencial de geração energética a partir do modelo USEPA é bastante interessante, pois mostra o que está sendo desperdiçado em aterros sanitários e emitindo gases de efeito estufa, por outro lado, com a adequação dos aterros e a implantação de projetos de geração energética, o problema da gestão de resíduos se minimiza juntamente com o da poluição do ar, e diversifica as fontes de energias renováveis.

Este potencial já aparece comum valor significativo quando se trata apenas das principais cidades da região Noroeste Paulista com maior volume de resíduos depositados, Portanto, esta fonte renovável é uma alternativa bastante importante para a diversificação da matriz energética nas demais localidades da região onde possui aterro sanitário, dessa forma, ampliando a geração de energia a partir de fontes alternativas e aliando-se a disposição adequada de resíduos sólidos como uma solução. 


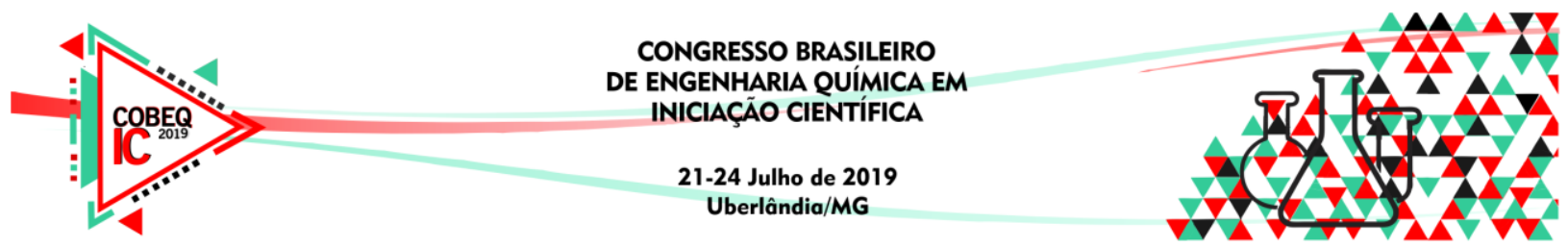

\section{NOMENCLATURA}

CETESB - Companhia Ambiental do Estado de São Paulo

$\mathrm{CH}_{4}$ - Gás metano

$\mathrm{CO}_{2}$ - Dióxido de carbono

GEE - Gases de efeito estufa

MW - Megawatt

USEPA - United States Environment al Protection Agency

\section{REFERÊNCIAS}

ALVES, P. A.; FELCA, A. T. A.; GLÓRIA, F. R.; BARROS, M. R. Estimativa do potencial energético de um aterro sanitário por meio de duas metodologias. XII Congresso Nacional de Meio Ambiente de Poços de Caldas. Poços de Caldas - MG. 2015.

AUDIBERT, L. J. Avaliação qualitativa e quantitativa do biogás do aterro controlado de Londrina.71 f. Dissertação (Mestrado). Programa de Mestrado em Edificações e Saneamento, Universidade Estadual de Londrina, Londrina, 2011.

JACO, R. O., FIGUEREDO, B. L., CLAUDINO G. O., BEZERRA J. D. S., CAVALCANTE R. F. Estimativa teórica da produção de biogás do aterro controlado. QUIXADÁ - CE, 2015.

PINÃS, V. A. J., VENTURINI, J. O., LORA, S. E. E., OLIVEIRA, A. M., ROALCABA, C. D. O. Aterros sanitários para geração de energia elétrica a partir da produção de biogás no Brasil: comparação dos modelos LandGEM (EPA) e Biogás (Cetesb) R. Bras. Est. Pop., Rio de Janeiro, v.33, n.1, p.175-188, 2016.

SANTOS, B. R., LIMA, C. K. A. Análise comparativa do biogás: processo em biodigestores e de aterro sanitário. Universidade Salvador (UNIFACS), v. 6, n. 1, p. 48-57, 2016.

SILVA, T. R. Metodologia para a determinação teórica da potência ótima conseguida a partir da combustão do biogás gerado em aterro sanitário: Estudo de caso do aterro sanitário de Itajubá-MG. 2012.

SOUZA, R. M. de; SERRA, J.C.V. ZUKOWSKI JUNIOR, J.C; SANTOS, D.R.R. Análise do potencial energético do biogás proveniente do aterro sanitário de Palmas/TO para geração de energia elétrica. Revista Científica da Ajes, v. 2, n.5, 2011. 